\title{
Agua, suelo y agricultura
}

\section{regenerativa}

Las prácticas regenerativas a gran escala en agrosistemas de México tienen el potencial de restaurar la salud ambiental en cuencas y acuiferos.

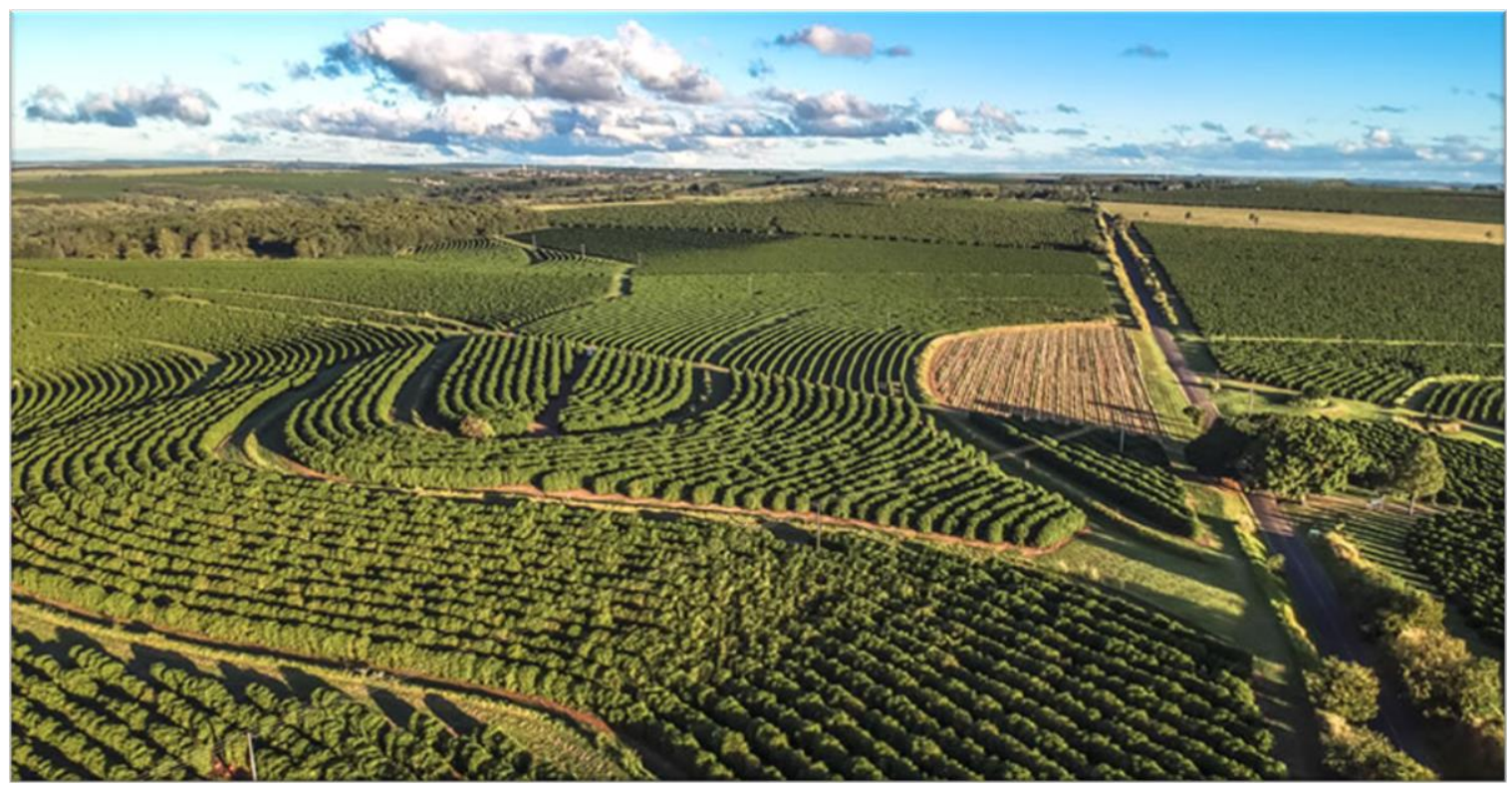

Nuestra sociedad está presenciando el surgimiento de una mayor conciencia sobre la huella ecológica de nuestra alimentación (Billen et al., 2027).

La cantidad excesiva de agroquímicos y láminas de riego han creado desequilibrios ambientales en diversas partes del mundo, desde abatimientos récord en niveles de acuíferos (Tiwari et al., 2009) hasta la desaparición de vida acuática en costas y mares (Rabalais et al., 2003). Además de los impactos en los sistemas hídricos y acuáticos derivados de nuestros hábitos alimenticios y prácticas comunes llevadas a cabo dentro del sector agroalimentario, existen otras consecuencias tales como la gran cantidad de emisiones de gases a efecto invernadero.

En relación con este último punto, las estimaciones a lo largo de la última década (Zeng et al., 2014) indican que la agricultura constituye una fuente neta de dióxido de carbono, cuando en realidad, este sector tiene el potencial de convertirse en un sumidero de carbono siempre y cuando se incorporen buenas prácticas en el manejo de los suelos (Northrup et al., 2021). La agricultura regenerativa se define como "la rehabilitación del suelo con el objetivo de mantenerlo productivo el mayor tiempo posible para evitar la expansión agresiva a nuevas áreas", con la excepción de territorios abandonados, así como incluyendo actividades de reforestación y restauración de turberas, entre otros. La regeneración de los suelos no solo tiene implicaciones positivas en el balance de carbono terrestre, sino también se ve 
reflejada en una mayor productividad en los cultivos y forrajes. A diferencia de la agricultura orgánica, la cual disminuye la concentración excesiva de agroquímicos en los suelos y cuerpos de agua, la agricultura regenerativa permite producir más con una menor cantidad de insumos.

Si bien estas diferentes facetas de la agroecología han sido adoptadas bajo diferentes iniciativas globales, tales como los Objetivos para el Desarrollo Sustentable de la Naciones Unidas, entre otros, la adopción de estos esquemas a gran escala ha estado limitada por los precios que el consumidor debe de pagar. Dentro de este mismo contexto, la mayoría de los gobiernos hasta la fecha no han otorgado los incentivos necesarios para que la población pueda acceder a una alimentación basada en prácticas orientadas a regenerar los servicios ambientales que el agua, los suelos y los bosques proveen mientras que el argumento principal de sus detractores es que la única opción para seguir alimentando a los habitantes de este planeta es a través de los sistemas agroindustriales.

Sin embargo, investigaciones recientes sobre el costo real de los alimentos de la sociedad estadounidense han establecido que añadiendo los costos ambientales (contaminación del agua, degradación de suelo, pérdida de biodiversidad), los costos en términos de riesgos para la salud, así como el impacto económico, el consumidor tendría que pagar tres veces más de lo que actualmente está pagando.

Por otro lado, existen muchos estudios que han comprobado que es a través de un manejo integral del suelo, atendiendo ciertos aspectos como la fertilidad y la microbiología, se puede aumentar tanto la resiliencia de los suelos a extremos climáticos (principalmente a las sequías) y por ende una mayor estabilidad financiera para los agricultores. Por ejemplo, se cree que, en los Estados Unidos, los ingresos a largo plazo de una hectárea bajo estas prácticas pueden duplicar a los ingresos de una hectárea con métodos convencionales debido a un menor requerimiento de insumos, una menor pérdida de suelos y mayores rendimientos como resultado de su resiliencia ante el calentamiento global (Ej. Asseng et al., 2015).

Ante la evidencia de las ventajas que la agricultura regenerativa ofrece, sería deseable empezar a trabajar en una normatividad para fomentar, regular y certificar todo producto derivado de dichas prácticas. Estos estándares deberán incorporar diferentes requerimientos básicos tales como: evitar la degradación de los suelos; prevenir la contaminación de fuentes de agua aledañas al sitio; y promover el bienestar en la agricultura animal y de los trabajadores involucrados. Para lograr esto, es necesario contar con información e indicadores sobre la biodiversidad, la salud del suelo y los servicios ambientales (carbono y agua) generados por el sistema agrícola que quiera entrar en este tipo de esquema productivo.

Finalmente, es fundamental difundir que este tipo de agricultura ambientalmente responsable es posible en México. Para lograr esto, es necesario formular políticas públicas acompañadas de incentivos económicos para aquellos agricultores interesados en implementar este tipo de prácticas en sus tierras, tanto a nivel federal como a nivel estatal. De igual manera, los incentivos directos (ej. fiscales otorgados por los gobiernos, creación de mercados de carbono) y/o indirectos (ej. provenientes del lado del consumidor) deberán ser equitativos, esto es, que tanto los grandes productores como los pequeños puedan tener acceso a ambos incentivos.

Las prácticas regenerativas a gran escala en agrosistemas de México tienen el potencial de restaurar la salud ambiental en cuencas y acuíferos, principalmente en aquellos territorios dominados por las 
actividades agropecuarias. EI IMTA, como Centro Publico de Investigación, puede contribuir en la transformación del campo mexicano mediante la capacitación de agricultores en la implementación de prácticas más sostenibles y que beneficien a todas las partes involucradas, empezando por el medio ambiente.

\section{REFERENCIAS}

Asseng, S, Ewert, F, Martre, P et al. (2015) Rising temperatures reduce global wheat production. Nature Climate Change, 5 (2). pp. 143-147. ISSN 1758-678X https://doi.org/10.1038/nclimate2470

Billen, G., Aguilera, E., Einarsson, R., Garnier, J., Gingrich, S., Grizzetti, B., ... \& Sanz-Cobena, A. (2021). Reshaping the European agro-food system and closing its nitrogen cycle: The potential of combining dietary change, agroecology, and circularity. One Earth, 4(6), 839-850. doi: 10.1016/j.oneear.2021.05.008

Northrup, D. L., Basso, B., Wang, M. Q., Morgan, C. L., \& Benfey, P. N. (2021). Novel technologies for emission reduction complement conservation agriculture to achieve negative emissions from row-crop production. Proceedings of the National Academy of Sciences, 118(28). doi: 10.1073/pnas.2022666118

Rabalais,N.N.,Turner,R.E.,Wiseman,W.J.,2002.GulfofMexicohypoxia,A.K.A.“TheDeadZone. Annu.Rev.Ecol.Syst. 33, 235-263.

Tiwari, V., J. Wahr, and S. Swenson (2009), Dwindling groundwater resources in Northern India, from satellite gravity observations, Geophys. Res. Lett., 36, L18401, doi:10.1029/2009GL039401.

Zeng, N., Zhao, F., Collatz, G. et al. Agricultural Green Revolution as a driver of increasing atmospheric CO2 seasonal amplitude. Nature 515, 394-397 (2014). https://doi.org/10.1038/nature13893 